\title{
OS PAIS FUNDADORES DA POLÍTICA MODERNA
}

\author{
Por Luiz Augusto Campos*
}

\begin{abstract}
MIGUEL, Luis Felipe. $O$ nascimento da política moderna: Maquiavel, utopia e reforma. Brasília: Ed. da UnB, Finatec, 2007. $133 \mathrm{p}$.
\end{abstract}

Lidar com temas clássicos e muito visitados em geral redunda em um hermetismo próprio das exegeses de segunda ordem. Por esse motivo, O nascimento da política moderna: Maquiavel, Utopia e Reforma, de Luis Felipe Miguel, surpreende por conjugar um estilo de escrita acessível com profundidade no tratamento das questões propostas. Como o próprio título indica, a intenção da obra é analisar autores do pensamento político moderno de quem herdamos a noção da política como uma esfera eminentemente social, autônoma em relação à moral e à religião, e que possui regras de conduta próprias.

Ainda que reconheça a pluralidade de pensadores que se debruçaram sobre o tema, Miguel defende que "é inegável que, por volta do século XVI, houve uma mudança decisiva no modo de pensar a política, da qual somos herdeiros" (p. 8). É justamente neste momento histórico de transição que ele localizará os principais formuladores da separação entre política e moral religiosa. Dentre esses pensadores destacam-se: Nicolau Maquiavel, precursor do realismo político; Thomas More, responsável por cunhar e significar

\footnotetext{
Cientista político pela UnB, mestre em Sociologia pela Universidade Federal do Rio de Janeiro (UFRJ) e, atualmente, doutorando em Sociologia no Iuperj e pesquisador do Grupo de Estudos Multidisciplinares da Ação Afirmativa (Gemaa-Iuperj).E-mail: lascampos@ gmail.com
} 
o conceito de utopia; e por fim os promotores da Reforma Protestante, sobretudo Martinho Lutero e João Calvino.

A obra se constitui numa mescla de análises teóricas com dados históricos elucidativos e instigantes, sem deixar de mencionar algumas breves e circunstanciais resenhas das diferentes interpretações existentes dos pensadores e assuntos tratados. Ao final do livro, encontram-se alguns resumos de parte da bibliografia citada, incentivo aos estudos posteriores dos leitores mais interessados. Além disso, merecem destaque algumas propostas experimentais de interpretação da política contemporânea a partir da atualização de determinadas teorias dos autores mencionados. Por isso, mais do que uma obra de introdução à reflexão política, talvez seja mais apropriado classificar $O$ nascimento da política moderna como uma espécie de guia comentado sobre as origens modernas da política tal como a reconhecemos hoje em dia.

$\mathrm{Na}$ Introdução, Miguel deixa claro que a profunda disparidade entre as obras consideradas não deve nos impedir de perceber que, "embora involuntariamente, todas contribuíram para a autonomização de uma esfera política, independentemente da religião (ou da moral)" (p. 8). Contudo, a despeito desse ponto em comum, não se deve perder de vista que a escolha dos autores que compõem o livro representa um importante deslocamento em relação à ortodoxia no campo da Ciência Política. Isto porque se Maquiavel é quase consensualmente considerado um clássico da disciplina, o mesmo não pode ser dito dos outros autores. A obra de Thomas More, por exemplo, está marcada pela ausência nos livros sobre a história da filosofia política (p. 8-9). Não raramente, ela é injustamente (des)classificada como um misto de reflexão política rasa e devaneios fantásticos semiliterários. Num dos raros casos em que o trabalho de More é comentado numa obra pertencente à Ciência Política, encontramos a seguinte análise: “Através de insensíveis graduações, a Utopia acaba por diluir-se no romanesco: muitos 
escritores de Utopias são apenas romancistas falidos" (Bobbio et al. 2002, p. 1290). Já Lutero, Calvino e os demais reformadores protestantes, apesar de reconhecidos como atores sociais relevantes historicamente, raramente são elevados ao grau de teóricos políticos. O livro, portanto, é uma interessante tentativa de recontar a história da política.

O primeiro capítulo ("Maquiavel e o desafio político") é marcado pela tentativa de desconstruir alguns lugares comuns sobre o autor florentino. De fato, a massa de interpretações sobre Maquiavel dentro da academia talvez já seja suficiente para afastar tradicionais clichês e enganos sobre sua obra. ${ }^{1}$ No entanto, não se pode esquecer que fora da Ciência Política e da Filosofia Política as visões negativas sobre o autor estão cada vez mais disseminadas. Isto pode ser facilmente atestado a partir da observação do conteúdo da crescente quantidade de obras que buscam "aplicar" os escritos de Maquiavel em áreas como management ou auto-ajuda. ${ }^{2}$ Nestas, o autor florentino ainda é referido erroneamente como o "rei do mal", o "little Nick" (o mesmo que "diabinho" para os ingleses), ou ainda como o pai do simplório adágio "os fins justificam os meios". Por esse motivo, a combinação de revisão bibliográfica, crítica teórica e linguagem acessível prestam um importante serviço ao pensamento de Maquiavel e à reflexão política como um todo.

$\mathrm{Na}$ Ciência Política, a centralidade de Maquiavel está diretamente relacionada ao seu entendimento da "política pela política", rechaçando as visões correntes da política como instância divina ou ferramenta moralizadora da sociedade (p. 30). Para Maquiavel, na política, os princípios morais ou as boas intenções não subsistiriam na ausência dos "meios materiais para a imposição do poder" (p. 19). Disto depreende-se que "muitas vezes é preciso fazer o mal para alcançar o bem" (p. 27), o que é bem diferente da máxima "os fins justificam os meios" atribuída à Maquiavel, embora ele nunca utilize tal expressão (p. 27). 
Como destaca Miguel, a discussão sobre meios maus e fins louváveis permanece útil atualmente para pensar, por exemplo, a "falsidade" dos políticos. Ele reformula o dilema de Maquiavel da seguinte forma: "quando existe ameaça da vitória de alguém que sabidamente levará toda uma coletividade para a catástrofe, vale a pena correr tão grande risco apenas para seguir o mandamento de não mentir?" (p. 29). Mesmo que a resposta seja afirmativa, diz Miguel, é preciso ter claro que Maquiavel não via a política como o lugar do vale-tudo. Ele apenas alerta para a funcionalidade das práticas más, inclusive para os projetos políticos que tenham a intenção de promover o bem. Em poucas palavras, Maquiavel aconselha que se deve sempre ter em mente que as regras morais da política são muito diferentes, às vezes opostas, às regras da moral religiosa.

Outro ponto forte do capítulo se refere à interpretação sobre o valor heurístico dos princípios maquiavelianos de fortuna e de virtú. Grosso modo, a fortuna se refere à sorte e ao destino, enquanto a virtú se refere às virtudes como a coragem e a sabedoria (p. 41). O político ideal é aquele que não é maltratado em demasia pelos caprichos da fortuna e que possui virtú suficiente, não só para tomar as decisões corretas mas, sobretudo, para se prevenir da fortuna caso ela se volte contra ele (p. 44). Como destaca Miguel, o valor da oposição entre virtú e fortuna reside no fato de ela traduzir analiticamente a "relação dialética que se estabelece entre vontade criadora e as limitações estruturais presentes na ação política" (p. 45) e, porque não dizer, da interface que marca sociedade e indivíduo (p. 40). Está explícito aqui outro deslocamento fundamental produzido pelo pensador florentino, qual seja, a interpretação da política como uma esfera eminentemente social, caracterizada por relações sociais contingentes que em nada tem a ver com qualquer poder divino.

O segundo capítulo ("O pensamento utópico do Renascimento") é visivelmente mais autoral que o primeiro. Nele, Miguel pretende reconstruir o pensamento utópico a partir dos tratados de 
Thomas More, que muito teriam a informar para a teoria política como um todo. Subjaz em toda a seção a idéia de que utopismo e realismo não seriam correntes tão opostas como se poderia imaginar (ver, sobretudo, p. 62 e 69).

Escrito apenas três anos após O Príncipe, A Utopia de Thomas More "granjeou a seu autor uma legião de admiradores" (p. 59). A descrição fantasiosa de uma terra que funcionaria perfeitamente graças à instituição de certas regras formais - isto é, a ilha Utopia se tornou quase um gênero literário depois da publicação de More (p. 87), conquistando a simpatia tanto de católicos fervorosos ${ }^{3}$ quanto de comunistas radicais. Dentre as diferentes dimensões que caracterizam os relatos utópicos cabe destacar a principal: o pressuposto de que um mundo perfeito pode ser construído a partir da própria sociedade e daqueles que a compõe, sem qualquer referência a divindades ou salvadores sobrenaturais (p. 62).

Segundo Miguel, a estrutura discursiva de A Utopia indica que além da projeção de uma sociedade perfeita, More construiu uma sutil crítica da sociedade em que vivia. A geografia de Utopia é incrivelmente semelhante à da Inglaterra e os problemas solucionados naquela são os que esta não conseguiu resolver (p. 68). Assim sendo, as utopias servem a outro importante intento, a saber, o de crítica social acompanhada sempre da proposição de soluções (p. 69).

Só a idéia de que a salvação não dependia de redentores sobrenaturais já significou uma importante contribuição de More à separação entre religião e política. Contudo, outra importante característica de Utopia é a grande liberdade religiosa. Ao introduzir tal instituição, um católico convicto como Thomas More estava longe de fazer alguma concessão em sua fé (p. 78). Isto porque ele via a extrema liberdade religiosa como meio para que a verdadeira fé triunfasse graças à razão e ao debate que surgiria entre os cidadãos. Temos aqui um bom exemplo da faceta realista de More, posto que ele defende a liberdade religiosa como meio de conter as investidas 
heréticas tão comuns na Europa do século XVI (p. 79), sem contudo abandonar a crença numa fé superior, portadora única do valor de verdade.

A introdução de Thomas More como um dos fundadores da representação moderna da política vai além do mero reconhecimento por Miguel da dívida histórica que o pensamento político teria com o pensador inglês. Na verdade, é possível perceber nos trabalhos de Miguel uma tendência de instrumentalizar o conceito de utopia e outros correlatos como uma profícua ferramenta de análise política. Desde Mito e discurso político (Miguel, 2000), passando por outros artigos de sua autoria (sobretudo Miguel, 1999 e 2006), ele expressa a sua preferência pelo estudo das "idéias-força", como os mitos políticos e as utopias. Para ele, "a utopia direciona a ação política e potencializa a insatisfação com o mundo existente" (Miguel, 2006, p. 93) e, por isso, "seu valor, muitas vezes, reside mais na indicação dos pontos problemáticos do ordenamento capitalista e no desafio de pensar diferente do que nas instituições propostas" (p. 92). Logo, o capítulo sobre as utopias consagra uma nova e profícua agenda de pesquisa utópica para a Ciência Política contemporânea.

O último capítulo ("A Reforma") tenta mostrar como as teorias dos reformadores protestantes aliadas ao jogo político europeu do século XVI permitiram a realização da separação entre religião e Estado "modificando o vínculo entre a Igreja e os príncipes profanos" (p. 91). Miguel tenta não só entender o surgimento das dissidências protestantes, mas também elucidar "porque estes homens do século XVI triunfaram e estabeleceram igrejas duradouras, repletas de fiéis e reconhecidas, enquanto muitos outros, antes, foram condenados como heréticos" (p. 93). Para ele, o sucesso da Reforma como um todo se deve justamente à defesa da separação entre Estado e Igreja, defesa esta vital para os Estados Absolutistas que então surgiam (p. 94). Por esse motivo, só teriam permanecido católicos os países que, de alguma maneira, haviam conquistado ou vieram a conquistar 
alguma influência sobre a religião (p. 94); os outros teriam visto na Reforma a solução para as ingerências do Vaticano em seus negócios políticos.

Além desses fatores mais materialistas, cabelembraros motivos teológicos que levaram os reformadores a postular a autonomia da política. De modo geral, esta perspectiva está relacionada à recusa luterana da noção de livre-arbítrio vista como uma "afronta à onipotência divina" (p. 99). As boas obras, na perspectiva de Martinho Lutero, não seriam motivos para salvação, mas apenas "meros sinais de que o indivíduo fora escolhido por Deus" (p. 99). Outro importante teólogo protestante, João Calvino, argumentaria em sentido semelhante, defendendo a idéia de predestinação. $\mathrm{O}$ que importa é que para ambos a salvação deixa de ser uma questão a ser administrada pela Igreja (através da venda de indulgências, por exemplo) para ser uma questão divina manifesta nas trajetórias individuais.

Por isso mesmo é que a maior parte dos intermediários entre o fiel e Deus deveriam ser abolidos. Ora, se as hierarquias rígidas da Igreja não deveriam mais interferir compulsoriamente na relação fiel-Deus, o Estado também não (p. 103). Era fundamental que se mantivesse "um espaço de liberdade de consciência resguardado do poder estatal" (p. 102). Calvino vai mais longe chegando a defender a submissão da própria fé ao governo. Sem esta submissão, aqueles dispostos a buscar Deus seriam perturbados pelos infiéis. Calvino chega ao extremo de propor um "direito dos povos à rebelião" (p. 109) caso o Estado não cumpra sua função de garantir a paz para a busca religiosa.

Após Nicolau Maquiavel, Thomas More e os reformadores protestantes, a gramática política nunca mais foi a mesma. Perguntas como "por que devemos obedecer?" ou "como a política se legitima?" ficaram carentes de respostas. Não surpreende que tais indagações tenham aparecido por escrito precursoramente apenas 
algumas décadas depois da publicação de $O$ Príncipe, por volta de 1570, com a circulação do pequeno e bombástico, Discurso da servidão voluntária, de Etienne de La Boétie (1999).

Sem mais poder recorrer às justificações religiosas, uma série de pensadores como Thomas Hobbes, John Locke, JeanJacques Rousseau e Immanuel Kant dedicarão parte de suas obras ao restabelecimento de uma base segura de legitimidade para o poder estatal. O "momento contratualista" só pode ser entendido se tivermos em mente que as críticas dos autores resenhados por Miguel já estavam colocadas e os questionamentos que eles incitaram já haviam sido explicitados por La Boétie. Como lembra Eleni Varikas (2003), nas primeiras décadas do século XVI, os renascentistas terminaram por "re-inventar o político como campo de liberdade", não demorando, porém, para que autores posteriores cuidassem de re-inventar "o natural como limite dessa liberdade humana que a religião já não estava em condições de conter”.

\section{Referências Bibliograficas}

BING, S. O que faria Maquiavel? Os fins justificam os maus. Rio de Janeiro: Rocco, 2002.

BOBBIO, N.; MATEUCCI, N.; PASQUINO, G. Dicionário de Política. 12. ed. Brasília: Ed. da UnB, 2002.

GREGÓRIO, F. Aplicando Maquiavel no dia-a-dia. São Paulo: Madras, 2008.

LA BOÉTIE, E. Discurso da servidão voluntária. São Paulo: Brasiliense, 1999.

LEDEEN, M. Maquiavel e a liderança moderna. São Paulo: Cultrix, 2002.

LEFORT, C. Le travail de l'oeuvre: Maquiavel. Paris: Gallimard, 1986. 
MIGUEL, L. F. (1999), Liberdade ou felicidade? A auto-realização humana em Marx, Gorz e Elster. Filosofia Política, Porto Alegre, n. 4, p. 176-210, 1999.

- Mito e discurso político: uma análise a partir da campanha eleitoral de 1994. Campinas: Ed. da Unicamp, 2000.

. Utopias do pós-socialismo: esboços e projetos de reorganização radical da sociedade. Revista Brasileira de Ciências Sociais, v. 21, n 61, p. 91-114, 2006.

RUBIM, H. Maquiavel para mulheres: a princesa. São Paulo: Campus, 2004.

VARIKAS, E. Naturalização da dominação e poder legítimo na teoria política clássica. Revista de Estudos Feministas, v. 11, n. 1, p. 171193, 2003. 